\title{
Melatonin action in tumor skeletal muscle cells: an ultrastructural study
}

\author{
S. Burattini ${ }^{a, *}$, M. Battistelli ${ }^{a}$, S. Codenotti ${ }^{\text {b }}$, E. Falcieri ${ }^{a}$, A. Fanzani ${ }^{\text {b }, 1}$, S. Salucci $^{\mathrm{a}, 1}$ \\ a Department of Biomolecular Sciences (DiSB), Urbino University Carlo Bo, Via Ca' Le Suore 2, 61029 Urbino, Italy \\ ${ }^{\mathrm{b}}$ Department of Molecular and Translational Medicine, Brescia University, Viale Europa 11, 25123 Brescia, Italy
}

\section{A R T I C L E I N F O}

\section{Article history:}

Received 14 October 2015

Received in revised form 19 February 2016

Accepted 19 February 2016

\section{Keywords:}

Apoptosis

Melatonin

Rhabdomyosarcoma

\begin{abstract}
A B S T R A C $T$
Melatonin (Mel), or $\mathrm{N}$-acetyl-5-methoxytryptamine, is a circadian hormone that can diffuse through all the biological membranes thanks to its amphiphilic structure, also overcoming the blood-brain barrier and placenta. Although Mel has been reported to exhibit strong antioxidant properties in healthy tissues, studies carried out on tumor cultures gave a different picture of its action, often describing Mel as effective to trigger the cell death of tumor cells by enhancing oxidative stress.

Based on this premise, here Mel effect was investigated using a tumor cell line representative of the human alveolar rhabdomyosarcoma (ARMS), the most frequent soft tissue sarcoma affecting childhood. For this purpose, Mel was given either dissolved in ethanol (EtOH) or dimethyl sulfoxide (DMSO) at different concentrations and time exposures. Cell viability assays and ultrastructural observations demonstrated that Mel was able to induce a dose- and time-dependent cell death independently on the dissolution solvent. Microscopy analyses highlighted the presence of various apoptotic and necrotic patterns correlating with the increasing Mel dose and time of exposure. These findings suggest that Mel, triggering apoptosis in ARMS cells, could be considered as a promising drug for future multitargeted therapies.
\end{abstract}

C 2016 Published by Elsevier GmbH.

\section{Introduction}

Human rhabdomyosarcoma (RMS) is the most common pediatric soft tissue sarcoma that arises from mesenchymal precursors with the potential to differentiate into skeletal muscle cells, but failing to complete myogenesis because of the presence of chromosomal aberrations (Zanola et al., 2012). RMS are aggressive tumors whose current chemotherapy is often unsuccessful (Dantonello et al., 2015), especially for the alveolar rhabdomyosarcoma (ARMS) that is characterized by a chromosomal translocation that generating the Pax3-Foxo1 fusion protein confers a more aggressive tumor phenotype and resistance to radiation therapy (Jothi et al., 2013). Currently, the employment of a multimodal therapy has increased the survival rate for patients with localized disease to $70 \%$ albeit with significant toxicity (Soundararajan et al., 2012). Despite that,

\footnotetext{
* Corresponding author. Fax: +39 0722304244.

E-mail addresses: sabrina.burattini@uniurb.it

(S. Burattini), michela.battistelli@uniurb.it (M. Battistelli), silvia.codenotti@unibs.it

(S. Codenotti), elisabetta.falcieri@uniurb.it (E. Falcieri), alessandro.fanzani@unibs.it

(A. Fanzani), sara.salucci@uniurb.it (S. Salucci).

1 These authors equally contributed to this work.
}

the therapy success for high risk patients is about $20-30 \%$ (Li et al. 2013), suggesting the need of more effective drugs.

Over the past years, Mel, beside its strong and documented antioxidant effects (Salucci et al., 2014b; Ganie et al., 2015), has been shown to act as an anticancer drug in different tumors (Sánchez-Hidalgo et al., 2012; Batista et al., 2014; Codenotti et al., 2015), for example via induction of the mitochondrial apoptosis (Bejarano et al., 2009) or attenuation of telomerase activity both in vivo and in vitro (Leon-Blanco et al., 2003).

Numerous studies have described its anticancer action in solid tumors and in leukemia through induction of the apoptotic cell death, leading to replacement of neoplastic cells with healthy cells (Sánchez-Hidalgo et al., 2012; Chuffa et al., 2015). Additionally, Kubatka et al. (2001) demonstrated the anti-tumor action of Mel in breast cancer in vivo, and this effect was then confirmed in clinical studies showing its protective effect from mammary carcinogenesis (Nowfar et al., 2002) and in other neoplastic diseases (Hong et al., 2014; Wu et al., 2015).

Here we have evaluated the ultrastructural changes occurring in the human alveolar RH30 cells upon administration of Mel dissolved either in EtOH (Salucci et al., 2014a) or DMSO (Jardim-Perassi et al., 2014) at different doses and exposure times. 


\section{Materials and methods}

\subsection{Cell culture}

Human RH30 cell line, purchased from the European Collection of Cell Cultures (ECACC; Salisbury, UK), was routinely tested for the expression of the Pax3-Foxo1 chimeric protein by both gene sequencing and western blot analysis using polyclonal anti-Foxo1 (H-128) antibody (Rabbit, sc-11350, Santa Cruz Biotecnology, Dallas, USA). Cells were also routinely tested for mycoplasma contamination using the LookOut Mycoplasma PCR Detection Kit (MP0035 Lookout, Sigma), according to the manufacturer's instructions. RH30 cells were cultured in RPMI 1640, supplemented with $10 \%$ heat-inactivated fetal bovine serum, $2 \mathrm{mM}$ glutamine, $1 \%$ antibiotics (Penicillin and Streptomycin) and maintained at $37{ }^{\circ} \mathrm{C}$ in humidified air with $5 \% \mathrm{CO}_{2}$ (Codenotti et al., 2015).

Mel (Sigma, St. Louis, MO, USA) was dissolved in $1 \%$ DMSO or $1 \%$ $\mathrm{EtOH}$ at the concentration of $100 \mathrm{mM}$. After 1 or $2 \mathrm{mM}$ Mel treatment, the cell behavior was monitored by means of the inverted microscopy. Trypan Blue exclusion assay was employed to quantify cell viability. The relative number of dead and living cells was obtained counting the number of stained (dead) and unstained (live) cells using a Neubauer chamber at reverted microscope. Student's $t$-test was applied for statistical analyses to compare results obtained in control versus treated samples; $P<0.05$ was considered as significance threshold.

\subsection{Scanning electron microscopy (SEM)}

RH30 cells were cultured on coverslips in Petri dishes. After washing with $0.1 \mathrm{M}$ phosphate buffer, adherent and suspended cells were fixed with $2.5 \%$ glutaraldehyde in $0.1 \mathrm{M}$ phosphate buffer for $1 \mathrm{~h}$. The suspended cell population was depositated on polylysine-coated coverslips and the samples were post-fixed with $1 \%$ osmium tetroxide $\left(\mathrm{OsO}_{4}\right)$ in $0.1 \mathrm{M}$ phosphate buffer solution (PBS) for $1 \mathrm{~h}$. After alcohol dehydration, the samples were critical point dried, gold sputtered and observed using a Philips 515 scanning electron microscope (Codenotti et al., 2015).

\subsection{Transmission electron microscopy (TEM)}

RH30-treated cells were washed and fixed with $2.5 \%$ glutaraldehyde in $0.1 \mathrm{M}$ PBS for $15 \mathrm{~min}$. The cells were scraped and centrifuged at $300 \mathrm{x} \mathrm{g}$ for $10 \mathrm{~min}$. The pellets were fixed in $2.5 \%$ glutaraldehyde for an additional $30 \mathrm{~min}$. The suspended cells were collected in Eppendorf, centrifuged and fixed for $45 \mathrm{~min}$ in glutaraldehyde. The samples were post-fixed in $1 \% \mathrm{OsO}_{4}$ for $1 \mathrm{~h}$, alcohol dehydrated and embedded in araldite. Thin sections were stained with uranyl acetate and lead citrate and analyzed using a Philips CM10 transmission electron microscope (Salucci et al., 2014b).

\subsection{Acridine orange (AO) and propidium iodide (PI) nuclei staining confocal laser scanning microscope (CLSM)}

Cells were fixed with 4\% paraformaldehyde in PBS ( $\mathrm{pH} 7.4$ ) for $30 \mathrm{~min}$, and suspended cells were deposited on poly-lysinated coverslips in Petri dishes. Adherent and suspendend samples were washed twice using PBS and then pre-treated with RNase A $10 \mu \mathrm{g} / \mathrm{mL}$ in PBS for $30 \mathrm{~min}$. After PBS washing samples were exposed to an equal mixture of PI ( $1 \mu \mathrm{g} / \mathrm{mL}$, Life Technologies) and AO $(1 \mu \mathrm{g} / \mathrm{mL}$, Life Technologies) diluted in PBS at room temperature (protected from light) for $10 \mathrm{~min}$ and then observed at CLSM (Leica Microsystems CMS GmbH); FICT and PI excitation were at 488 and $500 \mathrm{~nm}$, respectively, and their emission signals were detected at
617 and $525 \mathrm{~nm}$. CLSM images are presented as maximum intensity projection or single-plane images (Salucci et al., 2014b).

\subsection{Western blotting}

Protein homogenates were obtained by harvesting cells in a cold lysis buffer, composed by $20 \mathrm{mM}$ Tris- $\mathrm{HCl}$ ( $\mathrm{pH} 7.6$ ), $1 \%$ Nonidet $\mathrm{P} 40$, $0.5 \%$ sodium deoxycholate, $0.1 \% \mathrm{SDS}, 50 \mathrm{mM} \mathrm{NaCl}$ and a cocktail of protease inhibitors (Roche) plus phosphatase inhibitors (1 mM $\mathrm{Na}_{3} \mathrm{VO}_{4}$ and $4 \mathrm{mM} \mathrm{NaF}$ ).

Bradford reagent assay has been used to calculate protein concentration. Equal amount of protein samples were separated by SDS-PAGE under reducing conditions and transferred to polyvinylidine fluoride membranes. Sample were incubated with specific primary antibodies, Rabbit anti-Bax, polyclonal (Rabbit, sc-526, Santa Cruz Biotecnology, Dallas, USA) or Rabbit anti-Bcl2, polyclonal (Rabbit, sc-492, Santa Cruz Biotecnology, Dallas, USA) followed by peroxidase-conjugated secondary antibodies (anti-mouse IgG from Santa Cruz Biotechnology, Dallas, USA; antirabbit IgG from Thermo Scientific, Erembodegem, Belgium). The immunocomplexes were visualized using the enhanced chemiluminescence reagent (GeneSpin, Milan, Italy) and immune-reactive bands were quantified using densitometry analyses (Software Gel Pro Analyzer, version 4) (Codenotti et al., 2015).

\subsection{In silico analysis}

The primary mouse tumor cultures from RMS-bearing mice were previously obtained by Keller and colleagues (Rubin et al., 2011) and utilized for gene expression analysis by employing the microarray approach (Illumina Mouse Ref-8 BeadChip, v1.1). Data sets were deposited in the NCBI Gene Expression Omnibus database with the accession number GSE22520. To analyze Mel receptor expression, data were processed using the Partek ${ }^{\circledR}$ Genomics Suite software version 6.6 (Partek, St. Louis, USA). Briefly, the microarray raw dataset were reprocessed by the background correction, normalization and summarization of probe intensities, using the robust multiarray average analysis to determine the specific hybridizing signal for each probe set. After background correction, the data were transformed in base-2 logarithm. Quality control was also performed to identify the presence of arrays with poor quality and evaluate whether batch effect significantly affected the data.

A one-way analysis of variance (ANOVA) was performed to determine differentially expressed genes in mouse alveolar RMS in comparison to normal muscle samples. Fold change $>2$ and $p$ values $<0.05$ were used as criteria to evaluate significant difference in gene expression.

\section{Results}

To analyze whether Mel might affect cell survival in human alveolar RH30 cells, Trypan Blue exclusion assay was performed, revealing that Mel dissolved either in EtOH or DMSO significantly reduced the viability of RH30 cells in a time and dose dependent manner (Fig. 1A).

In support of this evidence, SEM (Fig. 1) and TEM (Figs. 2 and 3) analyses confirmed that Mel induced cell death of RH30 cells in a dose- and time-dependent manner and regardless of the dissolution solvent. In particular, while control adherent cells appeared to be fusiform or star-shaped (1B), $1 \mathrm{mM}$ Mel-treated cells showed a round shape morphology already after $24 \mathrm{~h}$ of treatment $(1 \mathrm{C}, 1 \mathrm{H})$. This effect was even increased after $48 \mathrm{~h}(1 \mathrm{D}, 1 \mathrm{I})$ or $72 \mathrm{~h}(1 \mathrm{E}, 1 \mathrm{~L})$ of Mel treatment and accompanied by the membrane blebbing process. After $2 \mathrm{mM}$ Mel treatment in EtOH (1F, 1G) or DMSO (1M-O), 

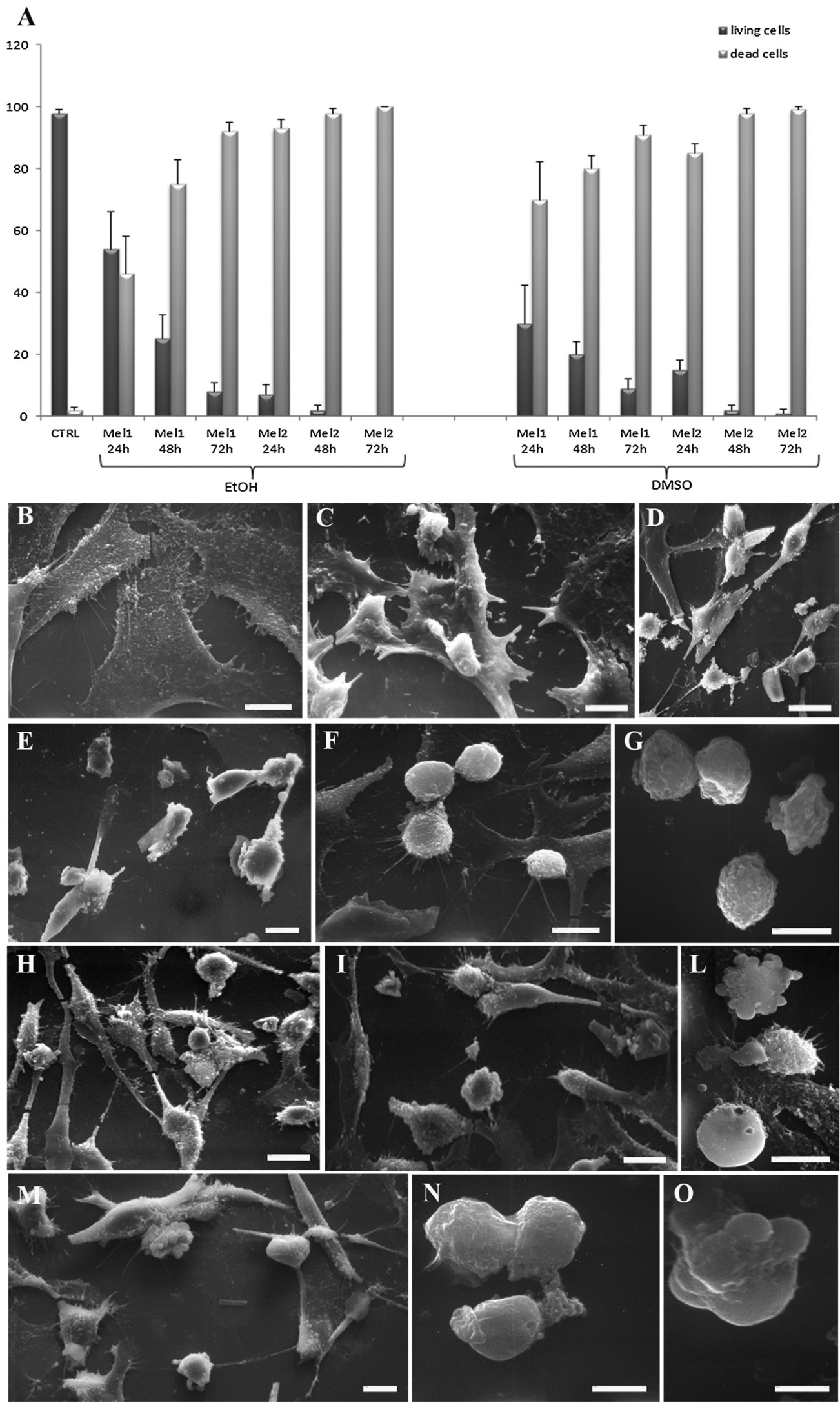

Fig. 1. Trypan blue exclusion assay. Histogram showing the percentages of living (dark grey column) and dead (light grey column) cells, under the different treatment conditions (A). Data are from three independent experiments and are shown as mean of value percentage \pm standard deviation. All Mel treatments are statistically significant versus control condition $(T$-test, $p<0.05)$.

SEM analysis of control untreated cells (B) versus Mel-treated cells (C-O); in detail, representative pictures showing cells treated with $1 \mathrm{mM}$ Mel (in EtOH) for 24-48-72 h (C, $\mathrm{D}$, E respectively) and $2 \mathrm{mM}$ Mel (in EtOH) for 24-48 (F, G respectively) or, alternatively, with $1 \mathrm{mM}$ Mel (in DMSO) for 24-48-72 h (H, I, L, respectively) and $2 \mathrm{mM}$ Mel (in DMSO) for $24(\mathrm{M})-48 \mathrm{~h}(\mathrm{~N}, \mathrm{O})$. Bars: $10 \mu \mathrm{m}$ B-O. 

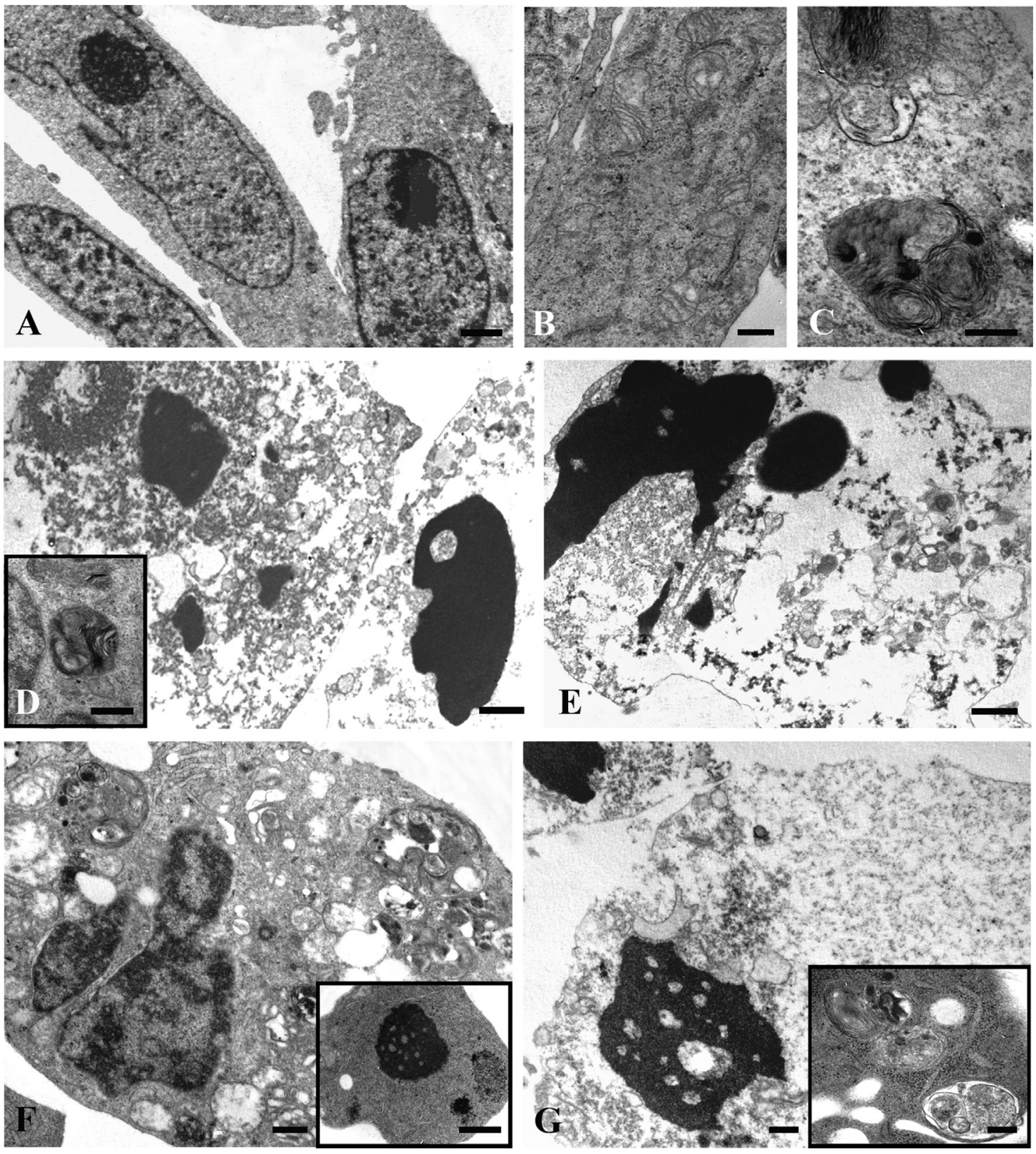

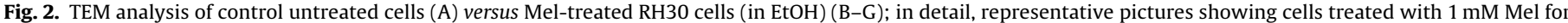
$24 \mathrm{~h}(\mathrm{~B}, \mathrm{C}), 48 \mathrm{~h}$ (D, inset D), $72 \mathrm{~h}$ (E) and $2 \mathrm{mM}$ Mel for $24-48 \mathrm{~h}$ (F, G respectively) Bars: A, B, G, F, inset D, $0.5 \mu \mathrm{m}$; C, inset G, $0.25 \mu \mathrm{m}$; D, E, inset F, $1 \mu \mathrm{m}$.

the diffuse cell damage occurring after $24 \mathrm{~h}(1 \mathrm{~F}, 1 \mathrm{M})$ and $48 \mathrm{~h}(1 \mathrm{G}$, $1 \mathrm{~N}, 10$ ) was characterized by rounding and blebbed cells.

TEM observations (Fig. 2) showed control cells having an elongated shape and intact subcellular structures (2A). Instead, after $1 \mathrm{mM}$ Mel administration for $24 \mathrm{~h}$, cells showed altered mitochondria (2B) and autophagic vacuoles (2C). Occasionally, early apoptotic nuclear features were observed (data not shown). After 48 and $72 \mathrm{~h}$, most of the treated cells appeared to be in late apoptosis $(2 \mathrm{D}, 2 \mathrm{E})$, whereas some of them showed a high number of autophagic-like structures (inset 2D).

Increasing Mel concentration up to $2 \mathrm{mM}$ for 24 and $48 \mathrm{~h}$ triggered different cellular alterations, including a diffuse cytoplasmic vacuolization (2F), chromatin condensation (inset F) and autophagic features (inset $G$ ). In particular, cells in secondary necrosis were observed after $2 \mathrm{mM}$ exposure for $48 \mathrm{~h}(2 \mathrm{G})$. Consistent with these results, the effects produced on RH30 cells by Mel dissolved in DMSO were similar (Fig. 3). Early and late apop- totic patterns could be observed after $1 \mathrm{mM}$ Mel at $24 \mathrm{~h}(3 \mathrm{~A}), 48 \mathrm{~h}$ (3B) and $72 \mathrm{~h}(3 \mathrm{C})$. Secondary necrosis as well as autophagic features appeared after $2 \mathrm{mM}$ Mel treatment at $24 \mathrm{~h}$ (3D, inset D, 3E) and $48 \mathrm{~h}(3 \mathrm{~F})$.

CLSM evaluation of RH30 cells exposed to Mel dissolved in DMSO was carried out by means of AO/PI double staining (Fig. 4). In Fig 4A, the uniform green labeling indicative of cellular healthy structures was visible in control condition. After AO and PI nuclear staining, treated cells (1 mM Mel for $24 \mathrm{~h}$, Fig. 4B) showed a green stain similar to controls, although displaying a more rounded morphology compared to untreated cells. After 48 and $72 \mathrm{~h}$, the number of apoptotic cells increased (Fig. 4C, inset C and D) and some cells with orange areas due to PI permeability were observed (Fig. 4C). Cells treated with $2 \mathrm{mM}$ Mel for $24 \mathrm{~h}$ (Fig. 4E, inset E) showed orange nuclei due to late apoptotic events and necrosis.

In accordance with the observed apoptotic response after $1 \mathrm{mM}$ Mel for 48 and $72 \mathrm{~h}$, Western blot analysis showed Mel promoting 

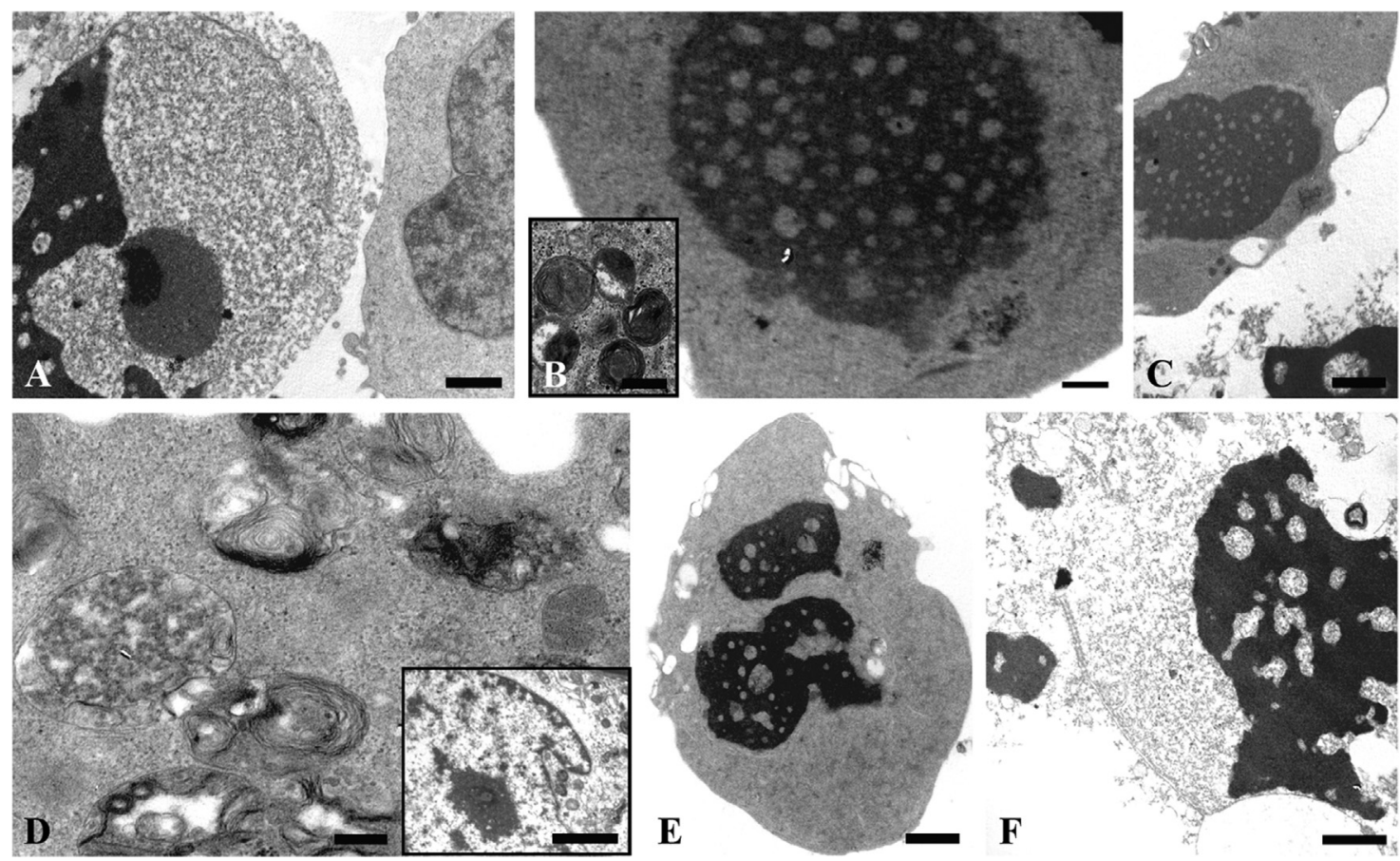

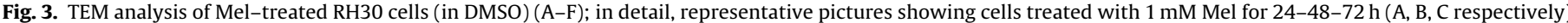
and $2 \mathrm{mM}$ Mel for $24(\mathrm{D}, \mathrm{E})$ and $48 \mathrm{~h}(\mathrm{~F})$ Bars: A, C, E, $1 \mu \mathrm{m} ; \mathrm{B}, \mathrm{F}, 0.5 \mu \mathrm{m}$; inset B, D, $0.25 \mu \mathrm{m}$; inset D, $2 \mu \mathrm{m}$.
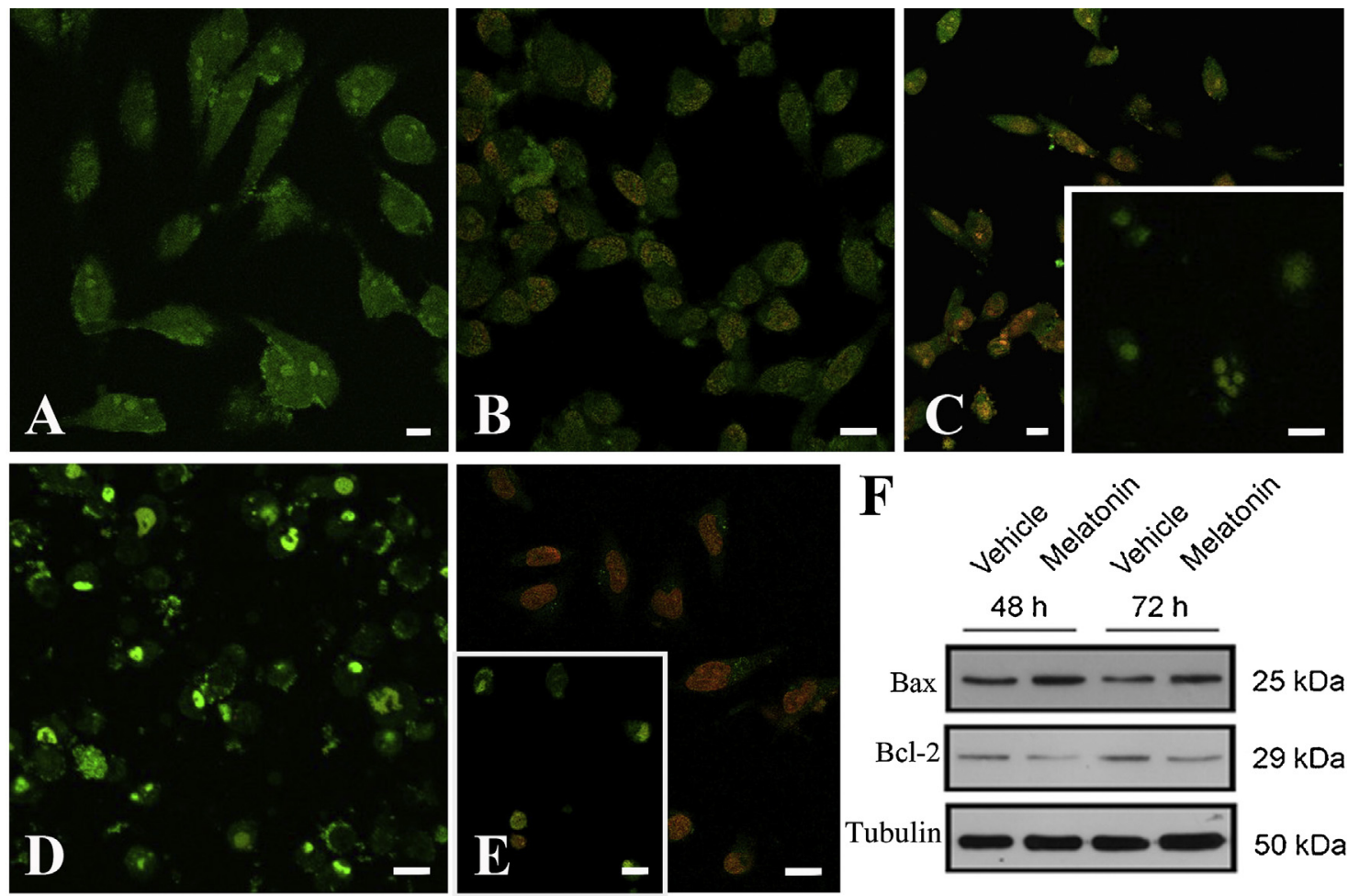

Fig. 4. CLSM analysis of control untreated (A) versus Mel-treated RH30 cells (in DMSO) after AO/PI double staining (B-E). In detail, representative pictures showing cells

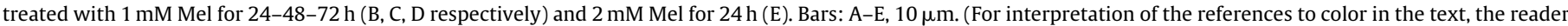
is referred to the web version of this article.)

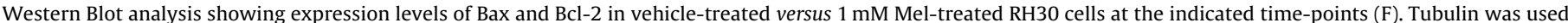
as protein loading control.

both an increase in the pro-apoptotic Bax expression and a decrease in the levels of anti-apoptotic Bcl-2 in comparison to untreated cells (Fig. 4F), therefore confirming that Mel induced apoptosis in RH30 cells.
Finally, an in silico analysis of microarrays data generated from primary mouse RMS tumor cultures (Keller et al., 2004; Keller and Capecchi, 2005) revealed that ARMS tumors could be sensitive to a receptor-dependent Mel action, as the transcript levels of Mel 
MT1

ILMN_1256388
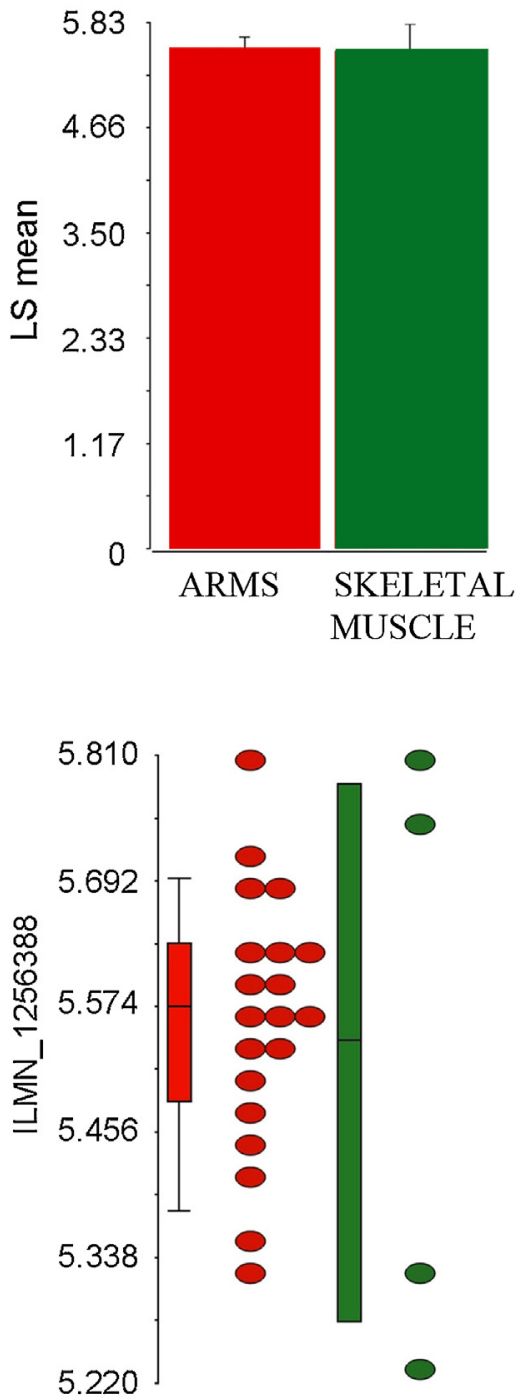

ARMS SKELETAL MUSCLE
MT2

ILMN_2770987
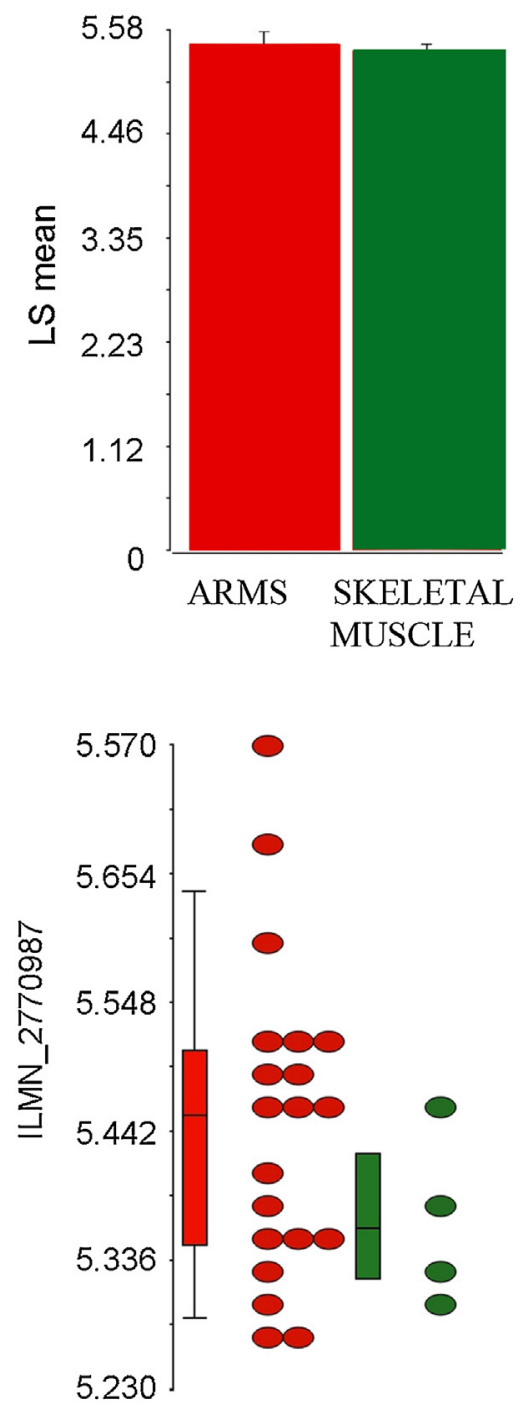

ARMS SKELETAL MUSCLE

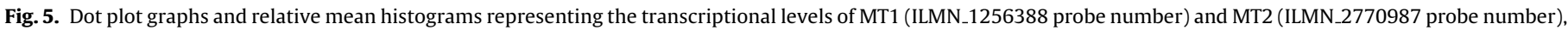
as detected in silico by performing a comparison between twenty ARMS samples and four skeletal muscle samples. $p$ value was not significant.

receptors MT1 and MT2 were detectable in ARMS subsets with expression levels comparable to those observed in skeletal muscle (Fig. 5).

\section{Discussion}

Epidemiological studies carried out over the past years have indicated that patients affected by some types of cancer have reduced bloody levels of Mel compared with healthy people (Mills et al., 2005; Lee, 2006). Since then, this pineal neurohormone Mel has been repeatedly described as a potential anti-cancer molecular tool given its demonstrated pro-apoptotic effect and oncostatic action towards different cancer cell lines (Bizzarri et al., 2013; Perdomo et al., 2013; Rodriguez et al., 2013; Hong et al., 2014), therefore contributing to cancer protection (Hrushesky et al., 2009; Mao et al., 2010; Bukowska, 2011; Santoro et al., 2012).

Based on this premise, here we focused on the ultrastructural effects induced by Mel on a human ARMS cell line carrying a unique molecular signature found among sarcomas, the Pax3-Foxo1 fusion protein arising from a specific chromosomal translocation (Jothi et al., 2013). RMS neoplasm is the most common soft tissue sarcoma of childhood. Although aggressive treatment of RMS could provide long-term benefit, resistance to prolonged therapies is a recurrent problem (Faye et al., 2015). The last decade has seen an extraordinary increase of studies on RMS for understanding how apoptotic mechanisms may contribute on cancer eradication. In this regard, the integrity of apoptosis pathways in RMS constitutes a critical determinant of the sensitivity to most current treatment strategies (Fulda, 2013).

In this work we have first confirmed previous findings showing the ability of Mel administered at pharmacological concentrations (Rodriguez et al., 2013) in triggering cell death of RMS cells (Codenotti et al., 2015); moreover, since the dissolution solvent represents an important variable potentially influencing the Mel action, typically the absolute EtOH (Salucci et al., 2014a; Salucci et al., 2014b) or DMSO (Martín-Renedo et al., 2008; Jardim-Perassi 
et al., 2014), here we have established that both these solvents did not influence the efficacy of neurohormone activity as death inducer in RH30 cell line.

Increasing both Mel doses and exposure time lead to late apoptosis and secondary necrosis a consistent number of RH30 cells. In this regard, our ultrastructural analyses revealed that $1 \mathrm{mM}$ Mel dose for up to 48 and $72 \mathrm{~h}$ represented the ideal conditions for triggering classical apoptosis-related morphological and biochemical changes, such as surface blebbing, chromatin margination and condensation, mitochondria alteration, cytoplasmic vacuolization, autophagic vacuoles accompanied by Bax activation and $\mathrm{Bcl}-2$ down regulation; in this case, $\mathrm{RH} 30$ cells maintained a morphological plasma membrane integrity and necrotic cells were detected only occasionally. On the other side, secondary necrosis and necrotic cell death appeared to be the major death response at very high Mel dose ( $2 \mathrm{mM}$ ). From a therapeutic point of view, killing cancer cells via apoptosis rather than necrosis could be considered a more preferable way, given that the appearance of necrosis in vivo might be accompanied by an inflammatory response typically associated to a more unfavorable outcome. Hence, the optimization of dosages for in vivo trials should take into account these preliminary in vitro observations.

The mechanisms by which Mel influences apoptosis have not been yet fully clarified (Sainz et al., 2003; Wölfler et al., 2001; Gong et al., 2003), although several reports have put forward the ability of Mel to elicit apoptotic effects through changes in the oxidative status. In this regard, a correlation between the increase in ROS production and the induction of Mel-driven apoptosis has been described in different cell lines (Büyükavci et al., 2006).

Mel action is classically mediated by the interaction with its membrane receptors (Radogna et al., 2009), i.e., MT1 and MT2, which seemed to be expressed also in a number of mouse ARMS tumors, as inferred through an in silico analysis that still awaits further in vitro and in vivo confirmation. Hence, the pro-apoptotic Mel effect on RH30 cells could be receptor dependent, although it is also possible that high doses of Mel may favor its simple diffusion across the cell membrane in a receptor-independent manner. On the whole, understanding whether Mel action in ARMS cells may be mediated or not (or at least partially) by its receptors will be important for identifying the pathways underlying its proapoptotic action; in addition, the synthesis and selection of mimetic compounds with increased activity could provide a further pharmacological tool for overcoming the growth of this solid tumor.

\section{Conclusions}

The data reported in this work indicate that Mel, when administered at pharmacological doses, can profoundly affect cell survival in RMS, the most frequent myogenic soft tissue sarcoma affecting children and adolescents (Ognjanovic et al., 2009; Meyer and Spunt, 2004). In particular, Mel was able to trigger an apoptotic program, independently on the dissolution solvent, therefore representing a promising drug for counteracting RMS tumor progression.

\section{References}

Batista, A.P., da Silva, T.G., Teixeira, A.A., de Medeiros, P.L., Teixeira, V.W., Alves, L.C., Dos Santos, F.A., Silva, E.C., 2014. Ultrastructural aspects of melatonin cytotoxicity on Caco-2 cells in vitro. Micron 59, 17-23.

Bejarano, I., Redondo, P.C., Espino, J., Rosado, J.A., Paredes, S.D., Barriga, C., Reiter, R.J., Pariente, J.A., Rodríguez, A.B., 2009. Melatonin induces

mitochondrial-mediated apoptosis in human myeloid HL-60 cells. J. Pineal Res. $46,392-400$

Bizzarri, M., Proietti, S., Cucina, A., Reiter, R.J., 2013. Molecular mechanisms of the pro-apoptotic actions of melatonin in cancer: a review. Expert Opin. Ther. Targets $17,1483-1496$.

Bukowska, A., 2011. Anticarcinogenic role of melatonin-potential mechanisms. Med. Pr. 62, 425-434.
Büyükavci, M., Ozdemir, O., Buck, S., Stout, M., Ravindranath, Y., Savașan, S., 2006. Melatonin cytotoxicity in human leukemia cells: relation with its pro-oxidant effect. Fundam. Clin. Pharmacol. 20, 73-79.

Codenotti, S., Battistelli, M., Burattini, S., Salucci, S., Falcieri, E., Rezzani, R., Faggi, F. Colombi, M., Monti, E., Fanzani, A., 2015. Melatonin decreases cell proliferation: impairs myogenic differentiation and triggers apoptotic cell death in rhabdomyosarcoma cell lines. Oncol. Rep. 34, 279-287.

Chuffa, L.G., Alves, M.D., Martinez, M., Camargo, I., Pinheiro, P., Domeniconi, R., Lupi Júnior, L.A., Martinez, F., 2015. Apoptosis is triggered by melatonin in an in vivo model of ovarian carcinoma. Endocr. Relat. Cancer, pii: ERC-15-0463.

Dantonello, T.M., Stark, M., Timmermann, B., Fuchs, J., Selle, B., Linderkamp, C. Handgretinger, R., Hagen, R., Feuchtgruber, S., Kube, S., Kosztyla, D., Kazanowska, B., Ladenstein, R., Niggli, F., Ljungman, G., Bielack, S.S., Klingebiel, T. Koscielniak, E., 2015. Tumour volume reduction after neoadjuvant chemotherapy impacts outcome in localised embryonal rhabdomyosarcoma. Pediatr. Blood Cancer 62, 16-23.

Faye, M.D., Beug, S.T., Graber, T.E., Earl, N., Xiang, X., Wild, B., Langlois, S., Michaud, J., Cowan, K.N., Korneluk, R.G., Holcik, M., 2015. IGF2BP1 controls cell death and drug resistance in rhabdomyosarcomas by regulating translation of cIAP1. Oncogene 34, 1532-1541.

Fulda, S., 2013. Molecular targeted therapies for rhabdomyosarcoma: focus on hedgehog and apoptosis signaling. Klin. Padiatr. 225, 115-119.

Ganie, S.A., Dar, T., Bhat, A., Dar, K., Anees, S., Masood, A., Zargar, M.A., 2015. Melatonin: a potential antioxidant therapeutic agent for mitochondrial dysfunctions and related disorders. Rejuvenation Res. 18 (June).

Gong, L.H., Ren, D.H., Xiong, M., Lu, Z.Q., Wang, X.M., 2003. Melatonin in in vitro apoptosis of H22 hepatocarcinoma cells. Zhonghua Zhong Liu Za Zhi 25, $550-554$.

Hong, Y., Won, J., Lee, Y., Lee, S., Park, K., Chang, K.T., Hong, Y., 2014. Melatonin treatment induces interplay of apoptosis, autophagy, and senescence in human colorectal cancer cells. J. Pineal Res. 56, 264-274.

Hrushesky, W.J., Grutsch, J., Wood, P., Yang, X., Oh, E.Y., Ansell, C., Kidder, S., Ferrans, C., Quiton, D.F., Reynolds, J., Du-Quiton, J., Levin, R., Lis, C., Braun, D., 2009. Circadian clock manipulation for cancer prevention and control and the relief of cancer symptoms. Integr. Cancer Ther. 8, 387-397.

Jardim-Perassi, B.V., Arbab, A.S., Ferreira, L.C., Borin, T.F., Varma, N., Iskander, A.S., Shankar, A., Ali de Campos, M.M., Zuccari, D.A., 2014. Effect of melatonin on tumor growth and angiogenesis in xenograft model of breast cancer. PLoS One 9, e85311.

Jothi, M., Mal, M., Keller, C., Mal, A.K., 2013. Small molecule inhibition of PAX3-FOXO1 through AKT activation suppresses malignant phenotypes of alveolar rhabdomyosarcoma. Mol. Cancer Ther. 12, 2663-2674.

Keller, C., Arenkiel, B.R., Coffin, C.M., El-Bardeesy, N., DePinho, R.A., Capecchi, M.R. 2004. Alveolar rhabdomyosarcomas in conditional Pax3:Fkhr mice: cooperativity of Ink4a/ARF and Trp53 loss of function. Genes Dev. 18 2614-2626.

Keller, C., Capecchi, M.R., 2005. New genetic tactics to model alveolar rhabdomyosarcoma in the mouse. Cancer Res. 65, 7530-7532.

Kubatka, P., Bojková, B., ciková-Kalická K, M., Mníchová-Chamilová, M., Adámeková, E., Ahlers, I., Ahlersová, E., Cermáková, M., 2001. Effects of tamoxifen and melatonin on mammary gland cancer induced by $\mathrm{N}$-methyl- $\mathrm{N}$-nitrosourea and by 7,12-dimethylbenz(a) anthracene respectively, in female Sprague-Dawley rats. Folia Biol. (Praha) 47, 5-10.

Lee, C.O., 2006. Complementary and alternative medicines patients are talking about: melatonin. Clin. J. Oncol. Nurs. 10, 105-107.

Leon-Blanco, M.M., Guerrero, J.M., Reiter, R.J., Calvo, J.R., Pozo, D., 2003. Melatonin inhibits telomerase activity in the MCF-7 tumor cell line both in vivo and in vitro. J. Pineal Res. 35, 204-211.

Li, S.Q., Cheuk, A.T., Shern, J.F., Song, Y.K., Hurd, L., Liao, H., Wei, J.S., Khan, J., 2013. Targeting wild-type and mutationally activated FGFR4 in rhabdomyosarcoma with the inhibitor ponatinib (AP24534). PLoS One 8, e76551.

Mao, L., Yuan, L., Slakey, L.M., Jones, F.E., Burow, M.E., Hill, S.M., 2010. Inhibition of breast cancer cell invasion by melatonin is mediated through regulation of the p38 mitogen-activated protein kinase signaling pathway. Breast Cancer Res. 12, R107.

Martín-Renedo, J., Mauriz, J.L., Jorquera, F., Ruiz-Andrés, O., González, P., González-Gallego, J., 2008. Melatonin induces cell cycle arrest and apoptosis in hepatocarcinoma HepG2 cell line. J. Pineal Res. 45, 532-540.

Meyer, W.H., Spunt, S.L., 2004. Soft tissue sarcomas of childhood. Cancer Treat. Rev. 30, 269-280

Mills, E., Wu, P., Seely, D., Guyatt, G., 2005. Melatonin in the treatment of cancer: a systematic review of randomized controlled trials and meta-analysis. J. Pineal Res. 39, 360-366.

Nowfar, S., Teplitzky, S.R., Melancon, K., Kiefer, T.L., Cheng, Q., Dwived, P.D. Bischoff, E.D., Moro, K., Anderson, M.B., Dai, J., Lai, L., Yuan, L., Hill, S.M., 2002 Tumor prevention by 9 -cis-retinoic acid in the $N$-nitroso- $N$-methylurea model of mammary carcinogenesis is potentiated by the pineal hormone melatonin. Breast Cancer Res Treat 72, 33-43.

Ognjanovic, S., Linabery, A.M., Charbonneau, B., Ross, J.A., 2009. Trends in childhood rhabdomyosarcoma incidence and survival in the United States, 1975-2005. Cancer 115, 4218-4226.

Perdomo, J., Cabrera, J., Estévez, F., Loro, J., Reiter, R.J., Quintana, J., 2013. Melatonin induces apoptosis through a caspase-dependent but reactive oxygen species-independent mechanism in human leukemia Molt-3 cells. J. Pineal Res. 55, 195-206. 
Radogna, F., Nuccitelli, S., Mengoni, F., Ghibelli, L., 2009. Neuroprotection by melatonin on astrocytoma cell death. Ann. N. Y. Acad. Sci. 1171, 509-513.

Rodriguez, C., Martín, V., Herrera, F., García-Santos, G., Rodriguez-Blanco, J., Casado-Zapico, S., Sánchez-Sánchez, A.M., Suárez, S., Puente-Moncada, N. Anítua, M.J., Antolín, I., 2013. Mechanisms involved in the pro-apoptotic effect of melatonin in cancer cells. Int. J. Mol. Sci. 14, 6597-6613.

Rubin, B.P., Nishijo, K., Chen, H.I., Yi, X., Schuetze, D.P., Pal, R., Prajapati, S.I., Abraham, J., Arenkiel, B.R., Chen, Q.R., Davis, S., McCleish, A.T., Capecchi, M.R., Michalek, J.E., Zarzabal, L.A., Khan, J., Yu, Z., Parham, D.M., Barr, F.G., Meltzer, P.S., Chen, Y., Keller, C., 2011. Evidence for an unanticipated relationship between undifferentiated pleomorphic sarcoma and embryonal rhabdomyosarcoma. Cancer Cell 19, 177-191.

Sainz, R.M., Mayo, J.C., Rodriguez, C., Tan, D.X., Lopez-Burillo, S., Reiter, R.J., 2003. Melatonin and cell death: differential actions on apoptosis in normal and cancer cells. Cell Mol. Life Sci. 60, 1407-1426.

Salucci, S., Burattini, S., Curzi, D., Buontempo, F., Martelli, A.M., Zappia, G., Falcieri, E., Battistelli, M., 2014a. Antioxidants in the prevention of UVB-induced keratynocyte apoptosis. J. Photochem. Photobiol. B 141, 1-9.

Salucci, S., Burattini, S., Battistelli, M., Baldassarri, V., Curzi, D., Valmori, A., Falcieri E., 2014b. Melatonin prevents chemical-induced haemopoietic cell death. Int. J. Mol. Sci. 15, 6625-6640.
Sánchez-Hidalgo, M., Guerrero, J.M., Villegas, I., Packham, G., de la Lastra, C.A 2012. Melatonin: a natural programmed cell death inducer in cancer. Curr. Med. Chem. 19, 3805-3821.

Santoro, R., Marani, M., Blandino, G., Muti, P., Strano, S., 2012. Melatonin triggers p53Ser phosphorylation and prevents DNA damage accumulation. Oncogene 31, 2931-2942.

Soundararajan, A., Abraham, J., Nelon, L.D., Prajapati, S.I., Zarzabal, L.A., Michalek, J.E., McHardy, S.F., Hawkins, D.S., Malempati, S., Keller, C., 2012. 18F-FDG microPET imaging detects early transient response to an IGF1R inhibitor in genetically engineered rhabdomyosarcoma models. Pediatr. Blood Cancer 59 485-492.

Wölfler, A., Caluba, H.C., Abuja, P.M., Dohr, G., Schauenstein, K., Liebmann, P.M., 2001. Prooxidant activity of melatonin promotes fas-induced cell death in human leukemic Jurkat cells. FEBS Lett. 502, 127-131.

Wu, S.M., Lin, W.Y., Shen, C.C., Pan, H.C., Keh-Bin, W., Chen, Y.C., Jan, Y.J., Lai, D.W. Tang, S.C., Tien, H.R., Chiu, C.S., Tsai, T.C., Lai, Y.L., Sheu, M.L., 2015. Melatonin set out to ER stress signaling thwarts epithelial mesenchymal transition and peritoneal dissemination via Calpain-mediated C/EBP $\beta$ and NFKB cleavage. J. Pineal Res., http://dx.doi.org/10.1111/jpi.12295.

Zanola, A., Rossi, S., Faggi, F., Monti, E., Fanzani, A., 2012. Rhabdomyosarcomas: an overview on the experimental animal models. J. Cell Mol. Med. 16, 1377-1391. 